\title{
Evaluation of the Appropriateness of Patients Referring for Single-Photon Emission Tomography Myocardial Perfusion Imaging Based On ACCF/ASNC AUC 2009
}

\author{
Abedi $\mathrm{SM}^{1}$, Farsavian $\mathrm{A}^{2}$, Golshani $\mathrm{S}^{2}$, Cherati $\mathrm{JY}^{3}$, Mojaveri $\mathrm{SG}^{1}$ and \\ Mardanshahi $A^{* 1}$ \\ ${ }^{1}$ Department of Radiology, Mazandaran University of Medical Sciences, Iran \\ ${ }^{2}$ Department of Cardiology, Mazandaran University of Medical Sciences, Iran \\ ${ }^{3}$ Department of Biostatistics, Mazandaran University of Medical Sciences, Iran
}

\section{Research Article \\ Volume 3 Issue 1}

Received Date: February 02, 2020

Published Date: April 07, 2020

DOI: $10.23880 /$ ijnmrs-16000126

*Corresponding author: Alireza Mardanshahi, Mazandaran University of Medical Sciences,

Frahabad Road, Mazandaran University Of Medical Sciences, Sari, Iran, Tel: 989111521805; Email: amardanshahi@yahoo.com

\section{Abstract}

Introduction: Coronary artery disease causes one third of all mortality per year throughout the world. In patient with suspicions coronary artery disease many diagnostic imaging procedure obtained. ACCF/ASNC AUC2009 was developed as a guide in cardiology for evaluation of patient with cardiovascular disease. The aim of this study is the evaluation of appropriateness of patient referring to our nuclear medicine center according to the AUC-2009 lastly published by ACCF/ASNC.

Methods: All patients that referred to our center from 2017/02/03 to 2017/06/15 enrolled in this study. Based on the AUC2009 criteria, patients were classified as appropriate, inappropriate, uncertain and unclassified. Then the prevalence of each groups determined and the correlation with sex, age and myocardial perfusion scintigraphy results were evaluated.

Results: 875 patients were enrolled in this study. The mean age was $58.6 \pm 12$ years and $58.9 \%$ of all patients were female. Stress phase of MPI was performed with exercise test in 132 (15.3\%), dipyridamole stress test in 716 (83.1\%) and dobutamine stress test in $13(1.4 \%)$ of the patients. In 500 (57.1\%) of patients the results of MPI was abnormal. From all patients 72 individuals (8.2\%) referred for myocardial viability evaluation, $76(8.6 \%)$ had history of previous CABG, 77(8.8\%) had previous history of PTCA and 36(4.1\%) referred for preoperative evaluation of non-cardiac surgery. From all patients, 696(79.5\%) patients were found as "appropriate", $165(18.9 \%)$ as "inappropriate", 8 (0.9\%) as "uncertain" and 6(0.7\%) patients as unclassified based on ACCF/ASNM AUC 2009 criteria.

Conclusion: This study revealed the referring patients for MPI in our academic center are closely correlated to the ACCF/ ASNM AUC 2009 criteria. The probability of abnormal MPI result was significantly greater in appropriate group than other groups. No statistically significant difference was observed in age and gender among the groups. The most probable cause of referring for MPI in appropriate group was inability to perform exercise test (61\%) and the most probable cause of patient classified as inappropriate was ability to performing exercise test (45.5\%).

Keywords: Myocardial Perfusion Imaging; Cardiovascular Disease; Appropriate Use Criteria

Abbreviations: MPI: Myocardial Perfusion Imaging; SPECT: Single-Photon Emission Computed Tomography;
MPS: Myocardial Perfusion Scintigraphy; ACCF: American College of Cardiology Foundation. 


\section{International Journal of Nuclear Medicine \& Radioactive Substances}

\section{Introduction}

Coronary artery diseases cause one third of all mortality per year worldwide; though, in the developing countries, proportion of referrals for myocardial perfusion imaging (MPI) have not been studied [1]. Therefore, single-photon emission computed tomography (SPECT) as a technique for myocardial perfusion imaging has been performed in many countries [2,3]. Moreover, myocardial perfusion scintigraphy (MPS) investigates patients with probable coronary artery disease. Suitable use criteria (American College of Cardiology Foundation or ACCF) were developed and revised to reduce cost and radiation risk to patients in the investigation of stable ischemic heart disease [4,5]. In coronary artery patients, the assessment and diagnosis of the risk factors and lesions have variety of ways. To that end, non-invasive methods in this extent are exercise testing, echocardiography stress, cardiac nuclear scan, CT angiography and cardiac MRI.Due to the myocardial perfusion scan precision and appropriateness its application for diagnosing coronary artery disease diagnose is increasing [6,7].

In myocardial perfusion scan Technetium-99m (99mTc) and Thallium-201 (201Tl) are the most common radionuclides that were used in cardiac nuclear imaging. Using Gamma Camera, which is a detector for the gamma radiation, emitted rays from the radionuclide in the patient's body can be transformed to image of the target organ $[8,9]$.

Moreover, the ECG-gated SPECT is one of the major advances in SPECT that is very important in the field of left ventricular function determination. Gated SPECT actually is evaluating left ventricular function; hence, the aim of this study is evaluation of appropriates of patient referring to our nuclear medicine center according the AUC-2009 lastly published by the ACCF/ASNC [10,11].

\section{Methods}

All patients that referred to our center from 2017/02/03 to $2017 / 06 / 15$ were enrolled in this study. All patients' information including the age, gender, cardiovascular risk factors, cardiovascular signs and symptoms, other laboratory findings and treatments modalities was recorded. Based on the AUC-2009 criteria, patients classified as appropriate, inappropriate, uncertain and unclassified. Therefore, we study these four groups and based on each group prevalence their distribution was evaluated in different age, sex and myocardial perfusion scan. In this study, SPSS24 software was used for data analyzing. Moreover, for data analyzing and determining the communication between specifications and characteristics of patients, the logistic regression method and significant level of 0.05 were applied.

\section{Results}

875 patients enrolled in this study. The mean age was $58.6 \pm 12$ years and $516(58.9 \%)$ of patient was female. In (Table 1) show some parameters of the patients.

\begin{tabular}{|c|c|}
\hline Characteristic & Value \\
\hline No. of Patients & 875 \\
\hline Female gender, $\mathrm{n}(\%)$ & $516(59)$ \\
\hline Age(years), mean \pm SD & $58.6 \pm 12$ \\
\hline Exercise, $\mathrm{n}(\%)$ & $132(15.3)$ \\
\hline Dipyridamole, $\mathrm{n}(\%)$ & $716(83.2)$ \\
\hline Dobutamine, $\mathrm{n}(\%)$ & $13(1.5)$ \\
\hline Only rest study, $\mathrm{n}(\%)$ & $14(1.6)$ \\
\hline Abnormal SPECT Interpretation, $\mathrm{n}(\%)$ & $500(57.1)$ \\
\hline Viability assessment, $\mathrm{n}(\%)$ & $72(8.4)$ \\
\hline History of CABG, $\mathrm{n}(\%)$ & $76(8)$ \\
\hline History of PTCA, $\mathrm{n}(\%)$ & $77(9)$ \\
\hline Preoperative risk assessment, $\mathrm{n}(\%)$ & $36(4)$ \\
\hline
\end{tabular}

Table 1: Parameters of patients.

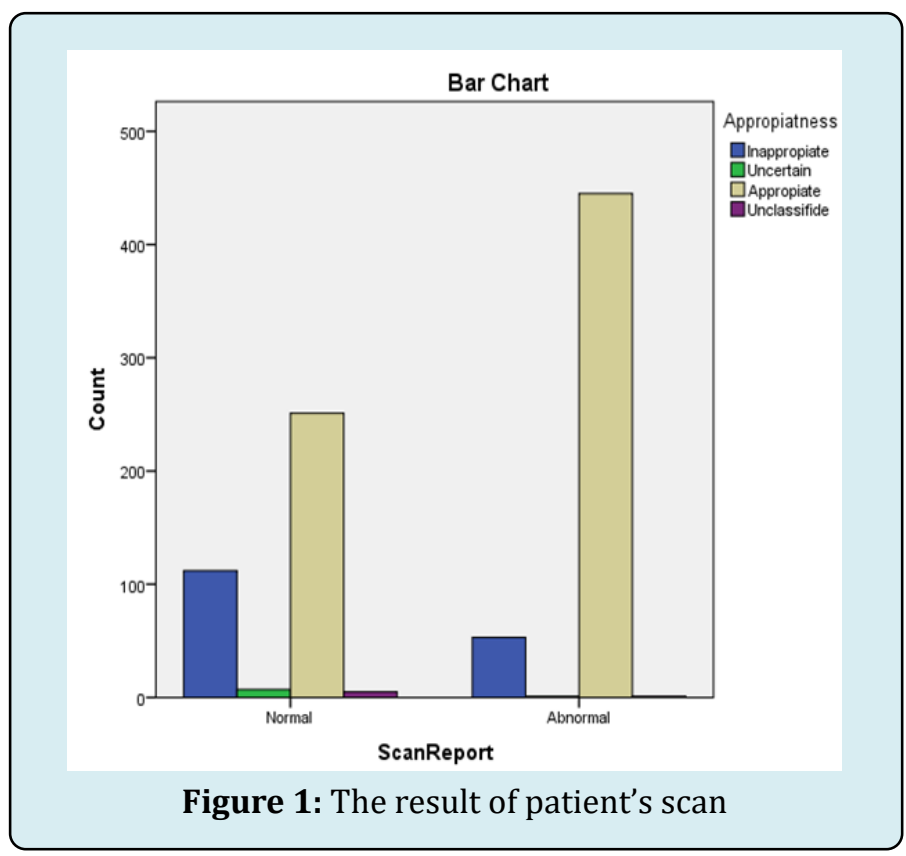

Totally for heart stress experiment, we assessed 57 patients (8.2\%) using stress-exercise test, 626 (89.9\%) dipyridamole test and 13 subjects (9.1\%) dobutamine test. Moreover, in the non-proportional group for heart scan, we used 75 patients $(45.5 \%)$ of the exercise test and 90 patients $(54.54 \%)$ of the dipyridamole stress test. From 875 patients who referred for heart scans, $72(10.3 \%)$ patients were referred for viable after myocardial infarction which 
diagnosed appropriately. Among 516 female patients, 94 women $(18.2 \%)$ were in the non-proportional group and $414(80.2 \%)$ were in the appropriate group while and 71 (19.8\%) male patients were in the non-proportional group and $281(78.5 \%)$ in the appropriate group. However, 375 patients (42.9\%) had normal heart scans, and 500 patients (57.1\%) had abnormal heart scans (Figure1).

In a general conclusion, 679 patients (79.5\%) are appropriate and 165 patients (18.9\%) are inappropriate by imaging based on ACCF/ASNC AUC 2009 (Figure 2).

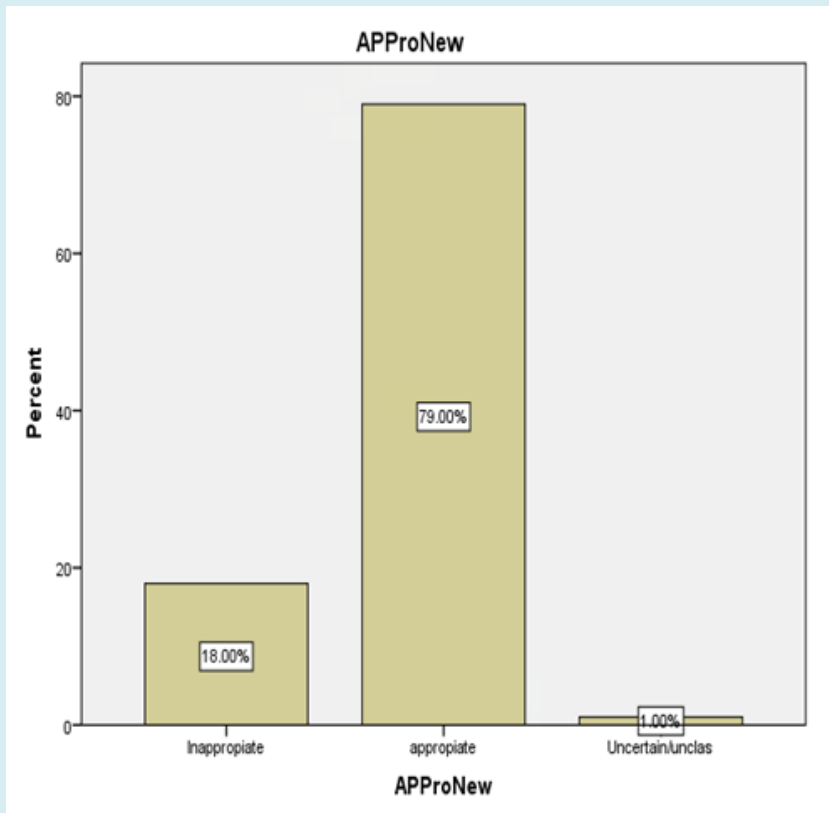

Figure 2: The proportion of patient's referrals for scan is in the study

Even though the most common reason for performing a heart scan in the proportion group was inability in exercise test $(61 \%)$ some people were in the inappropriate group because they werenot willing to do test exercise despite their ability to do it (45.5\%). Moreover, the average age of patients was $60 \pm 12$ for appropriate group and $57 \pm 11$ for inappropriate group.

\section{Discussion}

In this study, 875 patients that referred to the nuclear medicine department were studied within 4 months. The majority of patients (79.5\%) were in the appropriate group. A statistically significant difference was observed among the three groups including appropriate, inappropriate and unspecified $(\mathrm{P}=0.00)$. Koh $\mathrm{AS}$, et al. and Mehta $\mathrm{R}$, et al. also reported such results $[12,13]$. Among all the patents $63.9 \%$ in the appropriate group, $32.1 \%$ in the inappropriate group and $14.2 \%$ in other groups had abnormal scans. The difference between the groups was statistically significant $(P=0.00)$. These results are in agreement with the study performed by Mehta R, et al. [12]. Totally $8.2 \%$ of patients did exercise tests while this value for inappropriate group was $45.5 \%$ which is statistically significant $(\mathrm{p}=0.00)$. Likewise, in $89.9 \%$ of patients dipyridamole tests was performed while this value for inappropriate group was $54.5 \%$ which is statistically significant $(\mathrm{p}=0.00)$. PTCA patients and Patients with CABG history, appropriately detected by the ACCF/ASNC AUC 2009 criteria $(p=0.00)$. Most of the patients who referred for cardiac risk assessment for scanning were appropriate for the AUC 2009 criteria.

\section{Conclusion}

This study revealed the patients referring for MPI in our academic center are closely correlated to the ACCF/ASNM AUC 2009 criteria. The probability of abnormal MPI result was significantly greater in appropriate group than others groups. There was no statistically significant deference in age and gender among the groups. The most probable cause of referring for MPI in appropriate group was inability to perform exercise test (61\%) and the most probable cause of patient classified an inappropriate was ability to performing exercise test (45.5\%).

\section{References}

1. Giri S, Shaw LJ, Murthy DR, Travin MI, Miller DD, et al. (2002) Impact of diabetes on the risk stratification using stress single-photon emission computed tomography myocardial perfusion imaging in patients with symptoms suggestive of coronary artery disease. Circulation 105(1): 32-40.

2. Huang JY, Yen RF, Lee WC, Huang CK, Hsu PY, et al. (2019) Improved diagnostic accuracy of thallium-201 myocardial perfusion single-photon emission computed tomography with CT attenuation correction. J Nucl Cardiol 26(5): 1584-1595.

3. Cantoni V, Green R, Acampa W, Zampella E, Assante R, et al. (2019) Diagnostic performance of myocardial perfusion imaging with conventional and CZT singlephoton emission computed tomography in detecting coronary artery disease: A meta-analysis. J Nucl Cardiol pp: 1-18.

4. Kop M, Schroten NF, Mooi SSL, Tuinman PR (2017) Less Is More for Steroids in Severe Sepsis and Oxygen for the Critically Ill, but Maybe Not When Searching for Pulmonary Embolism in Syncope. American Journal of Respiratory and Critical Care Medicine 196(11): 1473- 
1475.

5. Yancy CW, Jessup M, Bozkurt B, Butler J, Casey DE, et al. (2016) 2016 ACC/AHA/HFSA focused update on new pharmacological therapy for heart failure: an update of the 2013 ACCF/AHA guideline for the management of heart failure: a report of the American College of Cardiology/American Heart Association Task Force on Clinical Practice Guidelines and the Heart Failure Society of America. Journal of the American College of Cardiology. 68(13): 1476-1488.

6. Patel MR, Calhoon JH, Dehmer GJ, Grantham JA, Maddox TM, et al. (2017) ACC/AATS/AHA/ASE/ASNC/SCAI/ SCCT/STS 2017 appropriate use criteria for coronary revascularization in patients with stable ischemic heart disease: a report of the American College of Cardiology appropriate use criteria task force, American Association for Thoracic Surgery, American Heart Association, American Society of Echocardiography, American Society of Nuclear Cardiology, Society for Cardiovascular Angiography and Interventions, Society of Cardiovascular Computed Tomography, and Society of Thoracic Surgeons. Journal of the American College of Cardiology. 69(17): 2212-2241.

7. Berman DS, Rozanski A, Slomka P, Nakanishi R, Dey D, et al. (2016) Value Based Imaging for Coronary Artery Disease: Implications for Nuclear Cardiology and Cardiac CT. Cardiac CT Imaging 349-380.
8. Rathmann SM, Ahmad Z, Slikboer S, Bilton HA, Snider DP, et al. (2019) The Radiopharmaceutical Chemistry of Technetium-99m. Radiopharmaceutical Chemistry pp: 311-333.

9. Sen DJ (2018) Nuclear Medicine as Radionuclide in Radiopharmaceutical in Scintigraphy. World J Pharm Res 7(13): 755-790.

10. Joergensen T, Hansson SH (2015) Evaluation of the left ventricular ejection fraction with gated IQ-SPECT myocardial perfusion imaging. Journal of Nuclear Medicine Technology 43(3): 193-200.

11. Maceira AM, NG Bellenger DJ (2019) Pennell, Assessment of cardiac function. Cardiovascular magnetic resonance pp: 192-207.

12. Mehta R, Ward RP, Chandra S, Agarwal R, Williams KA, et al. (2008) Evaluation of the American College of Cardiology Foundation/American Society of Nuclear Cardiology appropriateness criteria for SPECT myocardial perfusion imaging. J Nucl Cardiol 15(3): 337344.

13. Koh AS, Flores JL, Keng FY, Tan RS, Chua TS (2011) Evaluation of the American College of Cardiology Foundation/American Society of Nuclear Cardiology appropriateness criteria for SPECT myocardial perfusion imaging in an Asian tertiary cardiac center. J Nucl Cardiol 18(2): 324-330. 